\title{
Maintenance of Airway Hyperresponsiveness in Chronic Asthma May Be Mediated by Th2-Independent Mechanisms
}

\author{
Nora J. Lin ${ }^{1}$, Jane M. Schuh² and Cory Hogaboam ${ }^{*}, 2$ \\ ${ }^{I}$ Division of Allergy \& Immunology, University of Michigan Medical School, Ann Arbor, Michigan, USA \\ ${ }^{I}$ Department of Pathology, University of Michigan Medical School, Ann Arbor, Michigan, USA
}

\begin{abstract}
CD} 4+$, Th2-mediated inflammation is an important component of airway hyperresponsiveness (AHR) in allergic airway disease. IL-4 specifically interacts with the Type 1 IL-4 receptor comprised of IL-4R $\alpha$ and the common $\gamma$ chain, whereas IL-4 and IL-13 mediate their effects through a common receptor complex made up of IL-4R $\alpha$ and IL$13 R \alpha 1$ (i.e. the Type II IL-4 receptor). In this study, we examined the effects of impaired Th2 signaling on AHR using IL $4 R \alpha^{-/ /}$mice in a murine model of allergic asthma. IL-4R $\alpha^{-/-}$mice and control BALB/c $\left(\mathrm{IL}-4 \mathrm{R} \alpha^{+/+}\right)$mice were sensitized to and challenged with Aspergillus fumigatus. Airway disease was assessed at days 14, 28, 51, and 57 after intratracheal conidia challenge. AHR was evaluated by plethysmography after intravenous methacholine. Whole lung levels of cytokines and chemokines, and serum immunoglobulins were measured by specific ELISA. Paraffin-embedded lung sections were stained for histology. Bronchoalveolar lavage (BAL) fluid was cytospun for differential cell counts. While AHR was significantly reduced in IL-4R $\alpha^{-/-}$mice $(\mathrm{p}<0.01)$ at days 14 and 28 after conidia challenge, it was increased when compared to controls at later time points (days 51 and 57) even though Th2 cytokines were significantly decreased at day 57 , and total $\operatorname{IgE}$ and $\operatorname{IgG} 1$ levels were markedly decreased throughout the study $(\mathrm{p}<0.0001)$. Goblet cell metaplasia was also evident at days 51 and 57 in the knockout groups. These results demonstrate that airway hyperresponsiveness and mucus cell metaplasia in a model of allergic asthma can develop in the absence of a predominant Th2 signaling pathway, suggesting that Th2-independent mechanisms may arbitrate chronic stages of airway disease due to $A$. fumigatus.
\end{abstract}

Keywords: Th1/Th2, asthma, mice, IL-4R $\alpha$.

\section{INTRODUCTION}

IL-4 and IL-13 are considered to be key players in the pathophysiology of asthma and allergic disorders, although their individual roles are still unclear. Both are cytokines produced by $\mathrm{T}$ helper type 2 cells (Th2) cells, mast cells, and basophils, usually in response to antigen challenge [1] Because of their importance in orchestrating the airway inflammation and airway hyperresponsiveness seen in asthma [2-4], there has been considerable attention focused on research involving therapeutic targeting of IL-4, IL-13, or their signaling pathways.

IL-4 and IL-13 share several overlapping biological functions [1,5]. There are two known IL-4 receptors (type I and type II). IL-4 binds with high affinity to the $140-\mathrm{kD}$ IL4R $\alpha$ chain, and subsequent dimerization with the common gamma chain $(\gamma c)$ forms the type I receptor, found on hematopoietic cells $[1,6]$. Formation of this IL $4 R \alpha / \gamma c$ heterodimer then initiates signaling through the IL4R $\alpha$ chain, leading to STAT6 activation and gene transcription [6]. The IL4R $\alpha$ chain can also dimerize with IL-13R $\alpha 1$ instead of $\gamma c$, which forms the type II receptor, typically found on nonhematopoietic cells $[1,6]$. IL-13 binds to this heterodimer with low affinity. The IL4R $\alpha$ chain serves as a common signaling component of both the IL- 4 and IL-13 receptors that explains much of their overlapping functions.

*Address correspondence to this author at the Department of Pathology, University of Michigan Medical School, Ann Arbor, Michigan, USA; E-mail: hogaboam@med.umich.edu
Because of its central role in the IL-4 and IL-13 system, we investigated the effect of IL4R $\alpha$ chain deficiency in mice on airway hyperresponsiveness, goblet cell hyperplasia, and $\mathrm{TH} 2$ responses in vivo. Although others have utilized IL4R $\alpha^{-1-}$ mice to demonstrate that Th2 responses can and do develop in the absence of IL4R $\alpha$ in both parasite models [7, 8] and allergy models $[9,10]$, these studies have largely employed either more acute models or models using a non-aeroallergen as the sensitizing agent. We have previously described a murine model of chronic asthma induced by aeroallergen whereby there are sustained features of airway hyperresponsiveness, goblet cell metaplasia, and peribronchial fibrosis [11].

\section{MATERIALS AND METHODS}

Mice

Specific pathogen-free (SPF) female BALB/c (abbreviated IL-4R ${ }^{+/ 7}$ ) mice (8-12 weeks) were used in all experiments and were obtained from The Jackson Laboratory (Bar Harbor, ME). IL4R $\alpha^{-/-}$mice were obtained from The Jackson Laboratory and had a BALB/c genetic background. Animals were housed and maintained ( 5 mice per cage) under SPF conditions at the University Laboratory of Animal Medicine at The University of Michigan Medical School (Ann Arbor, MI) in accordance with the Institutional Animal Care and Use Committee guidelines.

\section{Chronic Model of A. fumigatus-Induced Allergic Asthma}

All mice were sensitized using a commercially available preparation of soluble Aspergillus fumigatus antigen per- 
formed as previously described in detail [11]. Seven days after the third intranasal challenge, each mouse received 5.0 x $10^{6}$ A. fumigatus conidia suspended in $30 \mu 1$ of $0.1 \%$ Tween 80 via the intratracheal route [11]. Although our previous studies in this model involved the analysis at various times up to approximately one month after the conidia challenge [11], in the present study we elected to follow wildtype and knockout mice up to day 57 after conidia. The rationale for this extension stemmed from our preliminary observation that greater amounts of fungal material were present in the lungs of the IL-4R $\alpha^{-/ 2}$ group at day 28 after conidia compared with the IL-4R $\alpha^{+/+}$group at the same time after conidia (data not shown). Thus, we were interested to observe whether this increased fungal burden in the knockout group had an adverse effect on their chronic lung function and morphology.

\section{Measurement of Airway Hyper-Responsiveness (AHR)}

Immediately before and at days 14, 28, 51, and 57 after intra-tracheal A. fumigatus conidia challenge, AHR was assessed in a Buxco plethysmograph (Buxco Electronics, Troy NY) as previously described [11]. Sodium pentobarbital (Butler Co., Columbus OH; $0.04 \mathrm{mg} / \mathrm{g}$ mouse body weight) was used to anesthetize mice before their intubation and ventilation with a Harvard pump ventilator (Harvard Apparatus, Reno NV). Once baseline airway resistance was established, each mouse received a low dose $(210 \mu \mathrm{g} / \mathrm{kg})$ and high dose $(420 \mu \mathrm{g} / \mathrm{kg})$ of methacholine via tail vein injection, and corresponding changes in airway hyper-responsiveness were monitored for approximately 3 minutes and calculated. The peak increase in airway resistance was recorded. After AHR analysis was completed, approximately $500 \mu \mathrm{l}$ of blood was removed from each mouse via ocular bleed and centrifuged at 15,000 $x \mathrm{~g}$ for 10 minutes to yield serum. A bronchoalveolar lavage (BAL) was then performed using $1 \mathrm{ml}$ of normal saline. Finally, whole lungs were dissected from each mouse and snap frozen in liquid $\mathrm{N}_{2}$ or fixed in $10 \%$ formalin for histological analysis (see below).

\section{Morphometric Analysis of Leukocyte Accumulation in BAL Samples}

Macrophages, lymphocytes, eosinophils, and neutrophils were enumerated in BAL samples cytospun (Shandon Scientific, Runcorn, UK) onto coded microscope slides. Each slide was stained with a Wright-Giemsa differential stain, and the average number of each cell type was determined after counting a total of 300 cells in 10 to 20 high-powered fields (x1000) per slide. A total of $1 \times 10^{6}$ BAL cells were cytospun onto each slide to compensate for differences in cell retrieval.

\section{Elisa and Serologic Analysis}

Murine IL-4, IL-5, IL-13, macrophage-derived chemokine (MDC), thymus and activation-regulated chemokine (TARC), and IFN- $\gamma$ protein levels were determined in $50 \mu 1$ samples from whole lung homogenates using a standardized sandwich enzyme-linked immunosorbent assay (ELISA) technique previously described in detail [12]. All ELISAs were screened to ensure the specificity of each antibody used. Recombinant murine cytokines and chemokines (R\&D Systems, Rochester MN) were used to generate the standard curves from which the sample concentrations were derived.
The limit of ELISA detection for each cytokine was consistently above $50 \mathrm{pg} / \mathrm{ml}$.

Total Ig levels were measured in serum samples using a specific ELISA. Serum levels of IgE, IgG1, and IgG2a at days $14,28,51$, and 57 after conidia in all mice were analyzed using complementary capture and detection antibody pairs for IgE, IgG1, and IgG2a (BD PharMingen, San Diego CA). Ig ELISAs were performed according to the IgE determination and $1 / 10$ for determination of IgG levels. Ig levels were then calculated from OD readings at $492 \mathrm{~nm}$, and $\mathrm{Ig}$ concentrations were calculated from a standard curve generated using $\operatorname{rgE}$, rIgG1, or rIgG2a (both standard curves ranged from 5 to $2000 \mathrm{pg} / \mathrm{ml}$ ).

\section{Whole Lung Histological Analysis}

Whole lungs from A. fumigatus-sensitized IL4R $\alpha^{+/+}$and IL4R $\alpha^{-/-}$mice before and at various times after $A$. fumigatus conidia challenge were fully inflated with $10 \%$ formalin, dissected, and placed in fresh $10 \%$ formalin for 24 hours. Routine histological techniques were used to embed the entire lung with paraffin, and $5 \mu \mathrm{m}$ sections of whole lung were stained with periodic acid-Schiff reagent (PAS). Morphological evaluations of inflammatory infiltrates and structural alterations were determined around blood vessels and airways using light microscopy at a magnification of x 1000 .

\section{Statistical Analysis}

All results are expressed as means \pm SEM (SE). A Student's unpaired t-test (Prism GraphPad software, San Diego, CA) was used to determine statistical significance between IL $4 \mathrm{R} \alpha^{+/+}$and IL4R $\alpha^{-/-}$mice at various times after the conidia challenge. Two separate, full time course (i.e. prior to and at days $14,28,51$, and 57 after conidia) experiments were performed. $\mathrm{P}<0.05$ was considered statistically significant.

\section{RESULTS}

\section{IL4R $\alpha^{-/-}$Mice Develop Increased Airway Hyperrespon- siveness at the Later Stages of Chronic Fungal Asthma}

Methacholine challenge induces airway hyper-responsiveness in mice with fungus-induced asthma [11]. As shown in Fig. (1), IL4R $\alpha^{+/+}$wild type mice at days 14 and 28 had significantly greater airway resistance $(p<0.05)$ in response to methacholine when compared to the IL4R $\alpha^{-/-}$mice (Day 14: $24.3 \pm 1.8$ vs $8.3 \pm 4.1$; Day $28: 29.5 \pm 1.4$ vs $8.2 \pm 3.8$ ). However, at the later stages of disease - day 57 after conidia challenge - IL4R $\alpha^{-/}$mice exhibited significantly more AHR $(p<0.05)$ than their wild type counterparts after methacholine administration $(22.9 \pm 3.8$ vs $10.1 \pm 3.2)$.

\section{IL4R $^{-/-}$Mice had Significantly Reduced T Cell Re- cruitment into the Airways at Late Stages of Disease}

Previous studies have shown that $\mathrm{T}$ lymphocytes are the major effector cells that mediate AHR in allergic airway disease [13]. Both IL-4 ${ }^{2}$ and IL-13 [14,15] play important, possibly independent, roles in this process. We examined $\mathrm{T}$ cell recruitment into the airways of IL4R $\alpha^{+/+}$wild type mice and IL4R $\alpha^{-/}$mice at both acute (days 14 and 28) and chronic (days 51 and 57) stages of Aspergillus-induced asthma. On days 28 and 57, there are significantly reduced numbers of $T$ cells found in the BAL samples of IL4R $\alpha^{-/-}$mice compared 

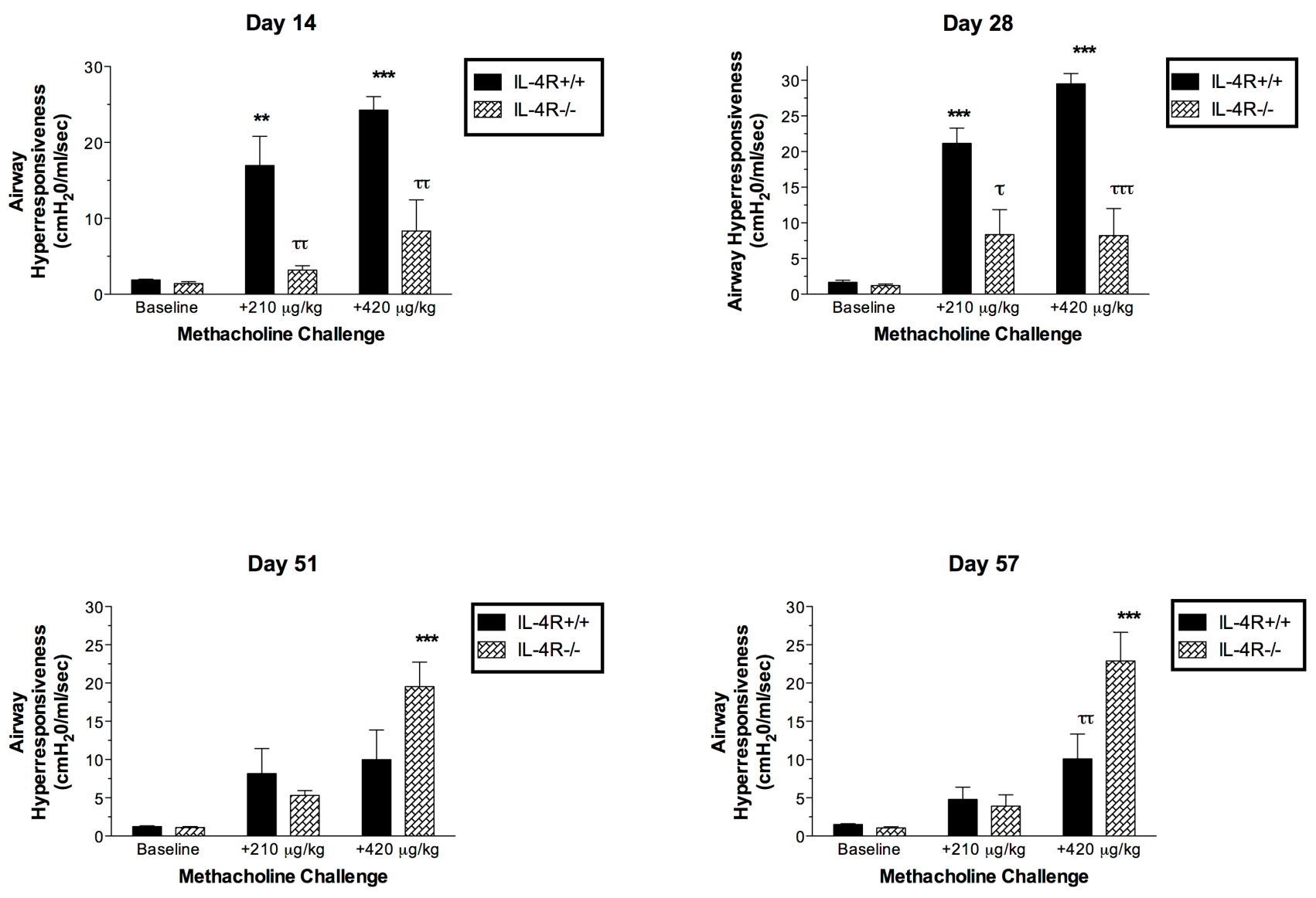

Fig. (1). Airway hyperresponsiveness in A. fumigatus sensitized IL-4R $\alpha$ wild-type $\left({ }^{+/+}\right)$and IL-4R $\alpha$ knockout $\left(\left(^{-/}\right)\right.$mice prior to and at various times after challenge with A. fumigatus conidia. Airway resistance was calculated at each time point before (i.e. baseline) and after intravenous methacholine challenge. Values are expressed as mean $\pm \mathrm{SEM} ; \mathrm{n}=5$ /group/time point. Significant differences are as follows: $* * \mathrm{P} \leq$ $0.01, * * * \mathrm{P} \leq 0.001$ compared with baseline resistance in the appropriate group. $\tau \mathrm{P} \leq 0.05, \tau \tau \leq 0.01, \tau \tau \tau \leq 0.001$ compared with airway resistance in IL-4R $\alpha^{+/+}$mice after methacholine challenge.

with wild type mice (Fig. 2). BAL eosinophils were also reduced in IL4R $\alpha^{-/-}$mice at all time points, but this difference did not reach statistical significance (Fig. 2). Interestingly, although neutrophils were low to undetectable on days 14,28 , and 51 after conidia, there was marked infiltration $(\mathrm{p}<0.0001)$ of neutrophils at day 57 after conidia in the IL $4 \mathrm{R} \alpha^{-/-}$mice compared to wild type mice (Fig. 2).

Increased Airway Hyperresponsive-Ness in IL4R $\alpha^{-/-}$ Mice is Not Mediated by Th2 Cytokines and Chemokines

Both IL-4 and IL-13 share the IL4R $\alpha$ chain as part of their receptor complex. Signaling through the IL4R $\alpha$ chain leads to downstream STAT6 activation and production of Th2 cytokines [16]. We examined the Th1 and Th2 cytokine levels in whole lungs of both IL $4 \mathrm{R}^{+/+}$wild type mice and IL $4 \mathrm{R} \alpha^{-/-}$mice had lower IL-4 levels at days 14, 28, and 57 after conidia and significantly reduced IL-4 levels $(\mathrm{p}<0.05)$ in the lung at day 57 post conidia (Fig. 3). IL-5 and IL-13 were also decreased at this and earlier time points, but this decrease did not reach statistical significance (Fig. 3). Similar to the Th2 cytokines, Th2 chemokines were also significantly decreased in IL4R $\alpha^{-/-}$mice. MDC was significantly decreased $(\mathrm{p}<0.05)$ at days 51 and 57 after conidia challenge, corresponding with the same time points at which increased
AHR was seen in the IL4R $\alpha^{-/-}$mice (Fig. 3). Interestingly, TARC was significantly decreased $(\mathrm{p}<0.05)$ in the IL4R $\alpha^{-/-}$ mice at all time points throughout the study (Fig. 3). IFN- $\gamma$ levels were not significantly changed throughout the study, with the exception of day 14 after conidia challenge (Fig. 3).

\section{IL4R $\alpha^{-/-}$Mice Develop Goblet Cell Metaplasia at Days 51 and 57 After Conidia}

Consistent with previous studies [17], IL4R $\alpha^{-/-}$mice showed a markedly significant decrease in serum $\operatorname{IgE}$ and IgG1 production at all times in the chronic fungal model (Fig. 4A,B). IgG2a was not significantly different in the two groups of mice (Fig. 4C).

As previously shown in the chronic fungal model, goblet cell metaplasia is a characteristic finding in A. fumigatussensitized mice challenged with live conidia [11]. PAS staining of whole lung sections from A. fumigatus-sensitized IL4R $\alpha^{+/+}$mice showed prominent goblet cell metaplasia in large airways at days 14 (Fig. 5A) and 51 (Fig. 5C) after conidia. In contrast, mice deficient in the IL4R $\alpha$ chain did not show goblet cell staining at day 14 (Fig. 5B) but interestingly, goblet cells were apparent at days 51 (Fig. 5D) and 57 (not shown) in the large airways of these mice. 
BAL D14

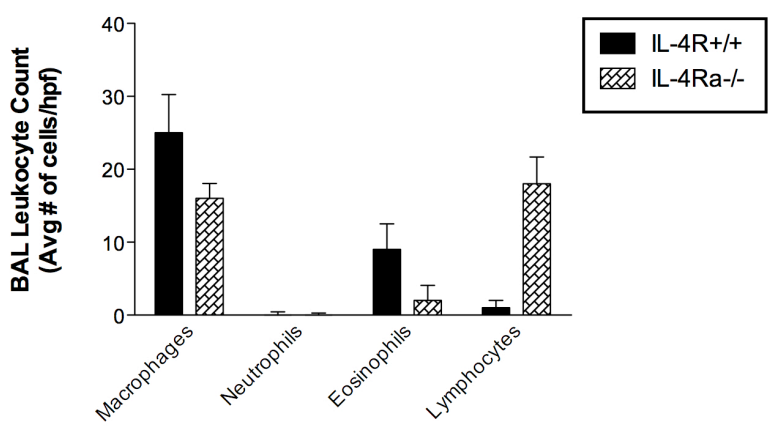

BAL D51

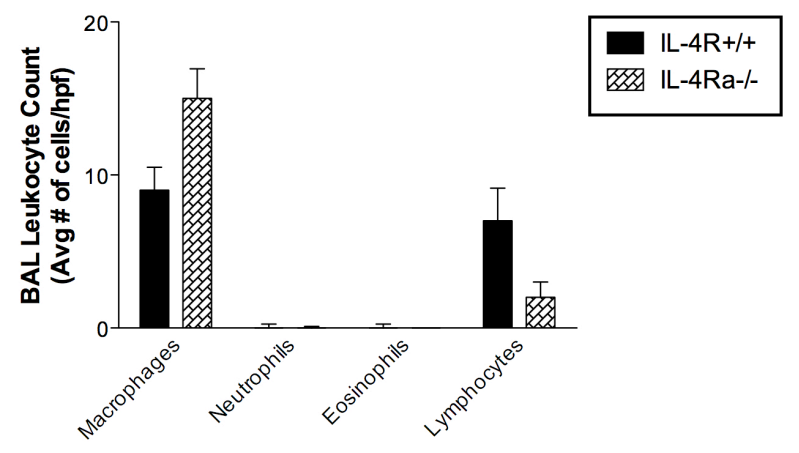

BAL D28

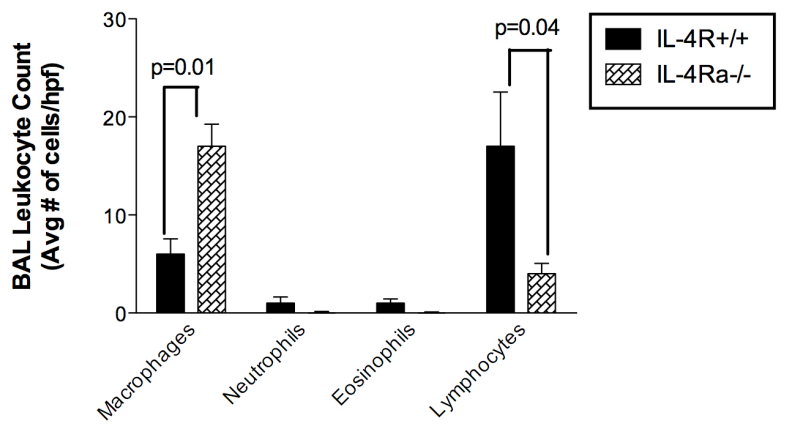

BAL D57

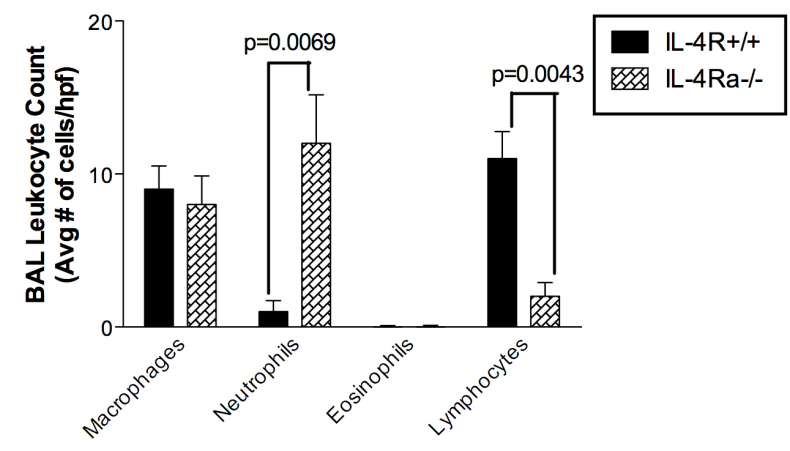

Fig. (2). Leukocyte counts in BAL samples in A. fumigatus sensitized IL-4R $\alpha$ wild-type $\left({ }^{+/+}\right)$and IL-4R $\alpha$ knockout $\left({ }^{-/}\right)$mice prior to and at days $14,28,51$, and 57 after challenge with $A$. fumigatus conidia. BAL samples were dispersed onto microscope slides via cytospin, and cells were differentially stained with Wright-Giemsa stain. A total of $1 \times 10^{6}$ cells were cytospun onto each slide and a minimum of 15 highpowered fields or 300 cells were examined in each cytospin. Values are expressed as mean \pm SEM. Significant differences between wild-type and knockout groups are indicated.

\section{DISCUSSION}

In the present study, we showed that in an established model of chronic asthma, deficiency of the IL4R $\alpha$ chain in A. fumigatus-sensitized mice did not result in the long-term elimination of AHR and goblet cell metaplasia as might be expected given the previously established importance of IL-4 and IL-13 signaling in the pathogenesis of asthma [14, 15, 18-20]. We observed that IL $4 \mathrm{R} \alpha^{--}$mice had increased AHR and mucus cell metaplasia in the more chronic stages of disease (i.e. days 51 and 57 after conidia challenge) but not in the earlier stages (i.e. days 14 and 28 after conidia). This is in contrast to previous studies that showed that the maintenance of AHR in IL4R $\alpha^{-/-}$mice in levels comparable to IL4R $\alpha^{+/+}$wild type mice after sensitization and challenge [10]. Their study, however, had important differences in methodology, including use of ovalbumin as the sensitizing antigen, and determination of AHR at much earlier time points.

Certain cytokines and many chemokines are well known for their overlapping functions and receptor binding patterns [21]. This is perhaps especially true in the setting of allergic airway disease $[2,9,14]$. To investigate whether a compensatory Th2 milieu was created in the absence of IL4R $\alpha$ signaling, we measured whole lungs levels of IL-4, IL-5, IL-13, as well as the Th2 Chemokines MDC and TARC. Interestingly, the increased AHR and goblet cell hyperplasia observed in the IL4R $\alpha^{-/-}$mice developed in the absence of a predominant Th2 cytokine and chemokine environment, as manifested by significantly decreased whole lung levels of IL-4, MDC and TARC. Serum levels of IgE and IgG1 were also markedly depressed. This is consistent with previous studies demonstrating that IL-4 [2], and IL-5 [4,22], and IgE [23] are not essential for development of antigen-induced AHR. Whole lung levels of IL-5 and IL-13 in our study approached, but did not reach statistically significant decreased levels in the later time points of the study. Such low level Th2 responses have been demonstrated in other studies using IL4R $\alpha^{--}$mice [17], suggesting that there are alternative sources of Th2 cytokines, such as NKT cells [17], that do not require signaling through the IL $4 \mathrm{R} \alpha$ chain.

Airway hyper-responsiveness in IL $4 \mathrm{R} \alpha^{-/-}$mice was significantly increased compared to IL $4 \mathrm{R} \alpha^{+/+}$wild-type mice at 
IL-4

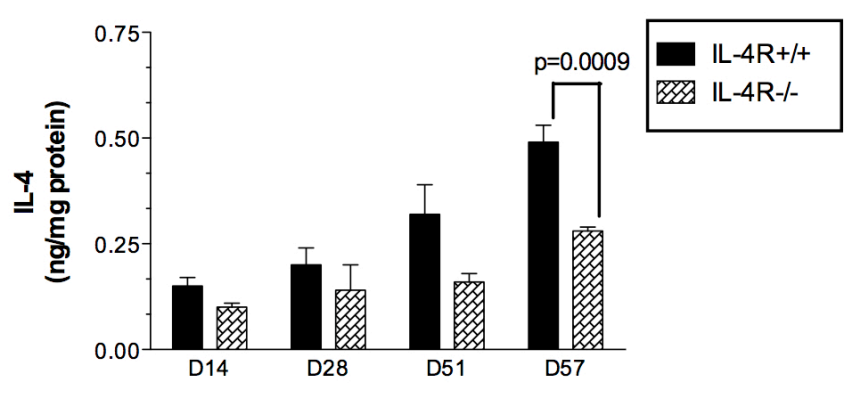

IL-13

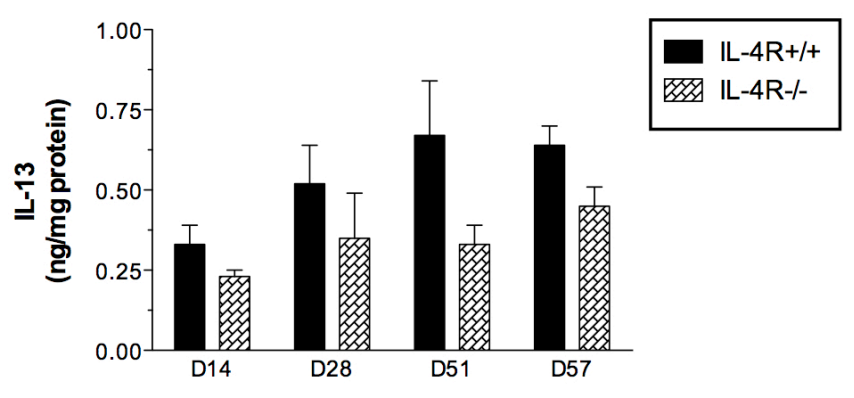

TARC

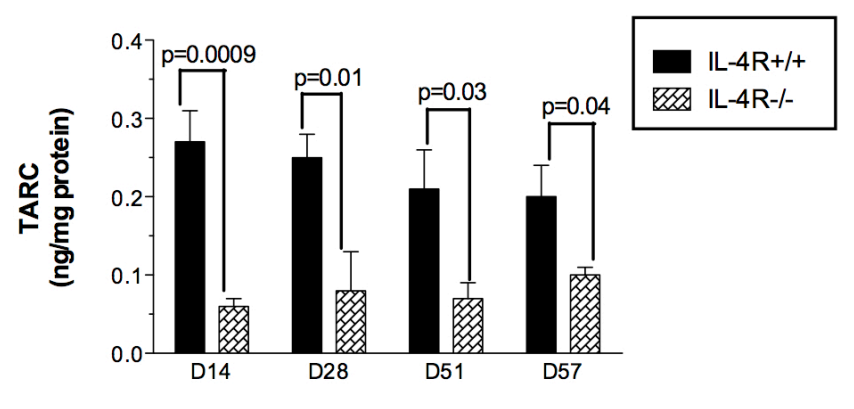

IL-5

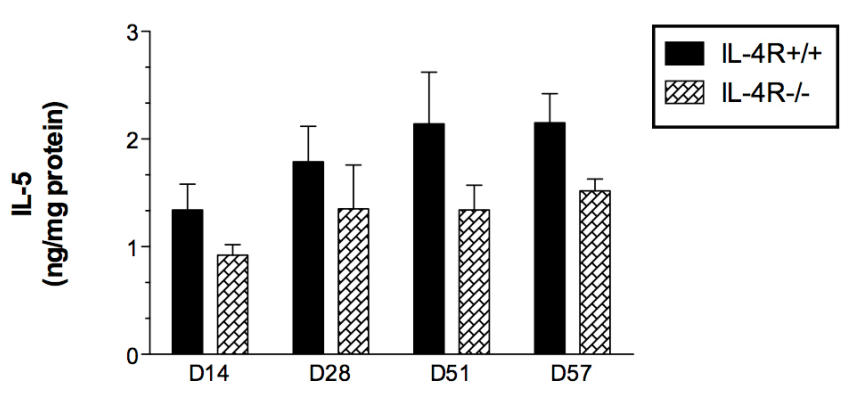

MDC

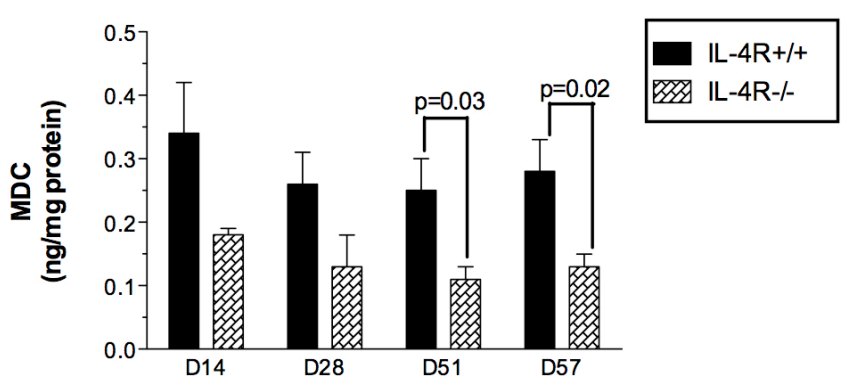

IFN- $\gamma$

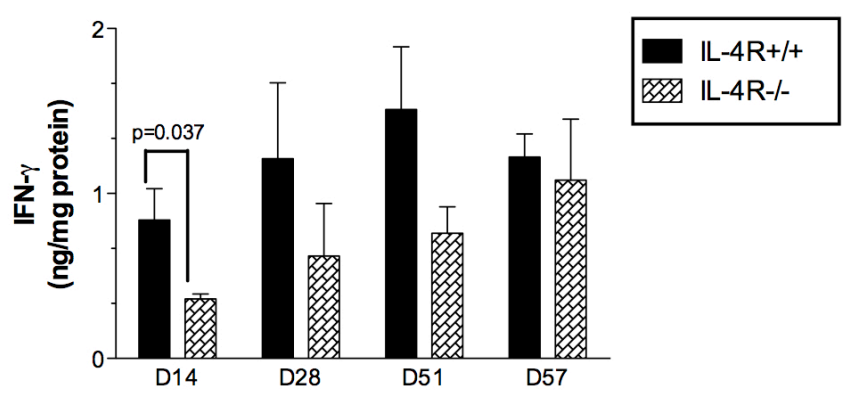

Fig. (3). Whole lung levels of IL-4, IL-5, IL-13, MDC, TARC, and IFN- $\gamma$ in A. fumigatus-sensitized IL-4R $\alpha$ wild-type $\left({ }^{+/+}\right)$and IL-4R $\alpha$ knockout $\left({ }^{-}\right)$mice prior to and at days 14, 28, 51, and 57 after challenge with A. fumigatus conidia. Cytokine and chemokine levels were measured by a specific ELISA as described in the Materials and Methods section. Values are expressed as mean \pm SEM; $\mathrm{n}=5 /$ group/timepoint. Significant differences between wild-type and knockout groups are indicated. 


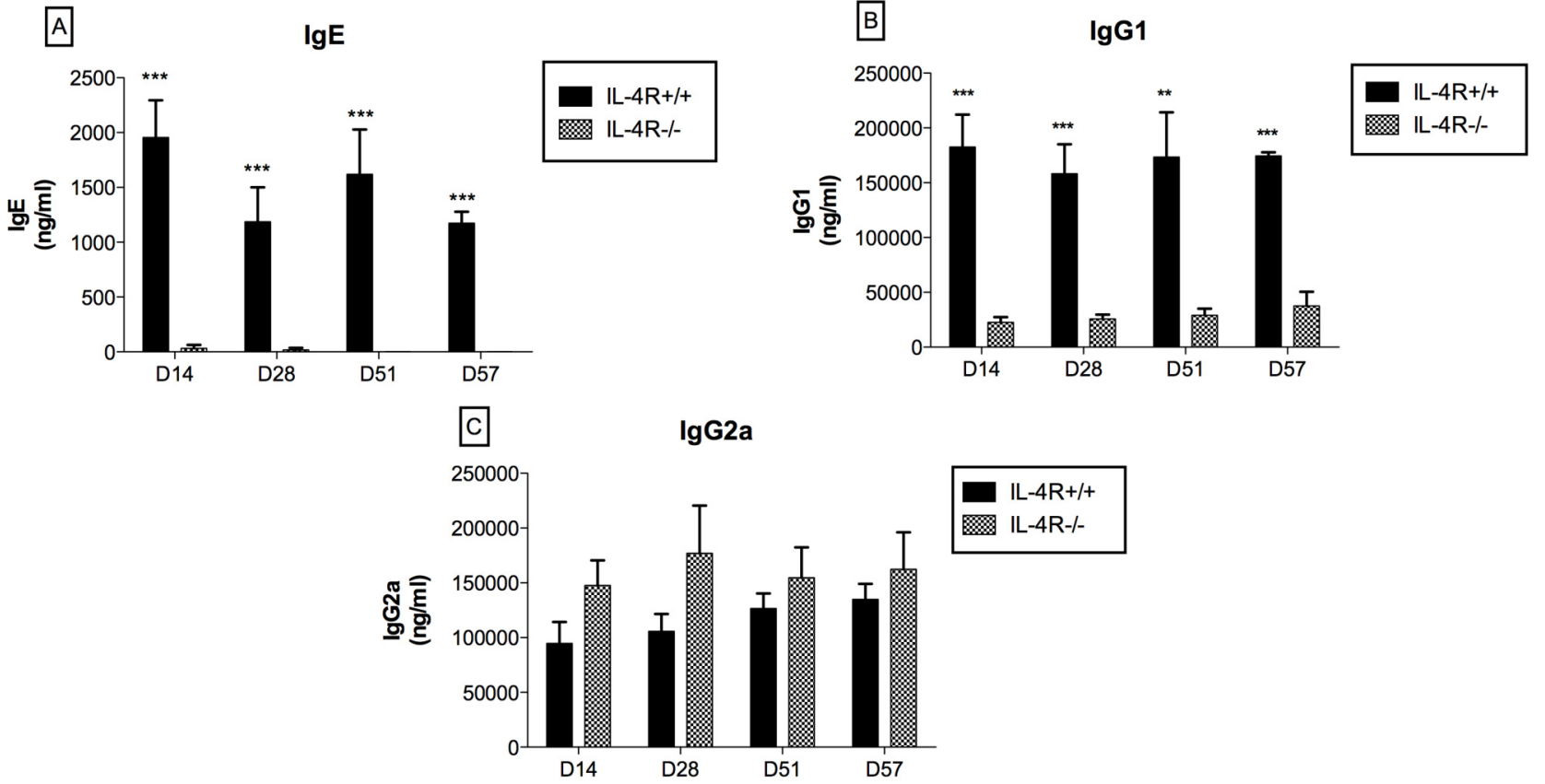

Fig. (4). Serum levels of $\operatorname{IgE}(\mathbf{A}), \operatorname{IgG} 1(\mathbf{B})$, and $\operatorname{IgG} 2 \mathrm{a}(\mathbf{C})$ in $A$. fumigatus-sensitized IL-4R $\alpha$ wild-type $\left({ }^{+/+}\right)$and IL-4R $\alpha$ knockout $\left({ }^{-/}\right)$mice prior to and at days 14, 28, 51, and 57 after challenge with $A$. fumigatus conidia. Ig levels were measured by a specific ELISA as described in the Materials and Methods section. Values are expressed as mean \pm SEM; $n=5 /$ group/time point. Significant differences between wild-type and knockout groups are indicated; $* * \mathrm{P} \leq 0.01, * * * \mathrm{P} \leq 0.001$.
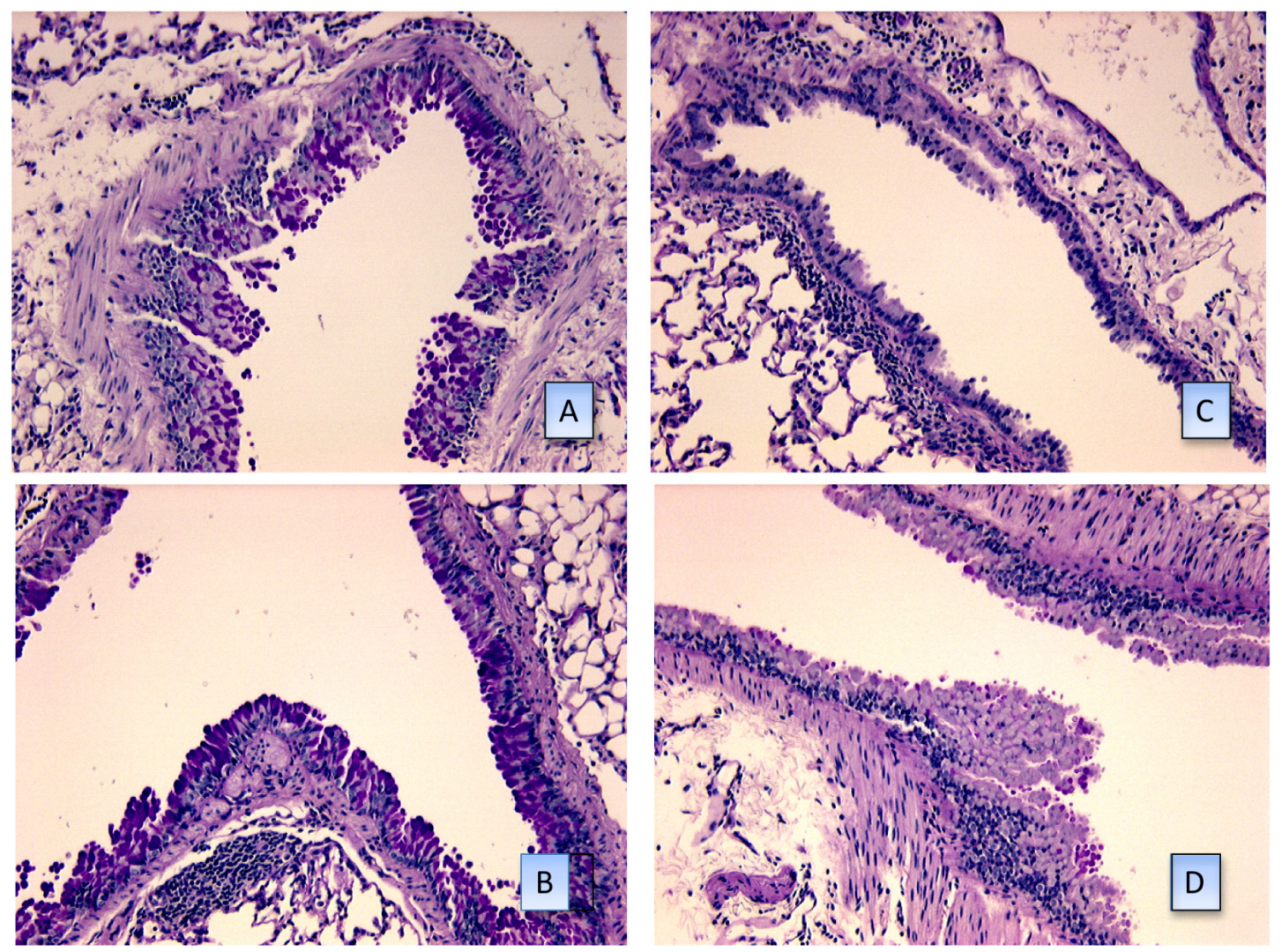

Fig. (5). Representative photomicrographs of PAS-stained whole lung sections from A. fumigatus-sensitized IL-4R $\alpha$ wild-type $\left({ }^{+/+}\right)(\mathbf{A}$ and C) and IL-4R $\alpha$ knockout $\left(^{--}\right)$(B and D) mice at days 14 (A and B) and 51 (C and D) after challenge with A. fumigatus conidia. Goblet cells (stained magenta) were prominent in the airways of the IL-4R $\alpha^{+/+}$mice at both times after the conidia challenge. In contrast, PAS-stained cells were observed in the IL-4R $\alpha^{-/-}$group at day 51 (D) but not at day 14 after conidia challenge. Original magnification was $200 x$ for each photomicrograph. 
days 51 and 57 after conidia challenge. Explanatory mechanisms were not apparent from our cellular and proteomic analysis in the present study. Although BAL neutrophil numbers were not different between the wild-type and knockout groups at day 51 after conidia, we were surprised by the marked neutrophilia in the bronchoalveolar lavage fluid in the IL4R $\alpha^{-/-}$mice at day 57 after conidia (Fig. 2). A similar pattern of sputum neutrophilia has been described in patients with severe, fatal asthma [24]. It is unclear at this time whether this phenotype represents a subtype of general asthma, or if there are other inflammatory mechanisms involved. The pattern of BAL neutrophilia, combined with mucus cell metaplasia and airway inflammation in a non-Th2 environment is also reminiscent of chronic obstructive pulmonary disease (COPD). Additional supportive findings of COPD would require quantitation of other inflammatory mediators including IL-8, TGF-B, matrix metalloproteinases, among others [25]. Nevertheless, it is unlikely that the increase in airway hyper-responsiveness observed in this study was due to increased neutrophil recruitment and/or activation in the knockout group. Further studies are required to elucidate the mechanism leading to increased airway reactivity to methacholine in the absence of IL-4R $\alpha$, and these future studies will be directed toward elucidating the significance of increased fungal material in the lungs of the knockout mice.

In summary, we have shown that IL $4 \mathrm{R} \alpha^{-/-}$mice develop AHR and mucus cell metaplasia in the absence of a Th2 cytokine environment. These findings suggest that certain features of chronic asthma including AHR and mucus cell metaplasia might be mediated by Th2 independent mechanisms.

\section{REFERENCES}

[1] Nelms K, Keegan AD, Zamorano J, Ryan JJ, Paul WE. The IL-4 receptor: signaling mechanisms and biologic functions. Annu Rev Immunol 1999; 17: 701-38.

[2] Cohn L, Tepper JS, Bottomly K. IL-4-independent induction of airway hyperresponsiveness by Th2, but not Th1, cells. J Immunol 1998; 161: 381-6.

[3] Corry DB, Grunig G, Hadeiba H, et al. Requirements for allergeninduced airway hyperreactivity in $\mathrm{T}$ and $\mathrm{B}$ cell-deficient mice. Mol Med 1998; 4: 344-55.

[4] Hogan SP, Matthaei KI, Young JM, Koskinen A, Young IG, Foster PS. A novel $\mathrm{T}$ cell-regulated mechanism modulating allergeninduced airways hyperreactivity in BALB/c mice independently of IL-4 and IL-5. J Immunol 1998; 161: 1501-9.

[5] de Vries JE. The role of IL-13 and its receptor in allergy and inflammatory responses. J Allergy Clin Immunol 1998; 102: 165-9. Kelly-Welch AE, Hanson EM, Boothby MR, Keegan AD. Interleukin-4 and interleukin-13 signaling connections maps. Science 2003; 300: $1527-8$
[7] Mohrs M, Holscher C, Brombacher F. Interleukin-4 receptor alphadeficient BALB/c mice show an unimpaired $\mathrm{T}$ helper 2 polarization in response to Leishmania major infection. Infect Immun 2000; 68: 1773-80.

[8] Noben-Trauth N, Paul WE, Sacks DL. IL-4 and IL-4 receptordeficient $\mathrm{BALB} / \mathrm{c}$ mice reveal differences in susceptibility to Leishmania major parasite substrains. J Immunol 1999; 162: 613240 .

[9] Mattes J, Yang M, Siqueira A, et al. IL-13 induces airways hyperreactivity independently of the IL-4R alpha chain in the allergic lung. J Immunol 2001; 167: 1683-92.

[10] Webb DC, Mahalingam S, Cai Y, Matthaei KI, Donaldson DD, Foster PS. Antigen-specific production of interleukin (IL)-13 and IL-5 cooperate to mediate IL-4Ralpha-independent airway hyperreactivity. Eur J Immunol 2003; 33: 3377-85.

[11] Hogaboam CM, Blease K, Mehrad B, et al. Chronic airway hyperreactivity, goblet cell hyperplasia, and peribronchial fibrosis during allergic airway disease induced by Aspergillus fumigatus. Am J Pathol 2000; 156: 723-32.

[12] Evanoff HL, Burdick MD, Moore SA, Kunkel SL, Streiter RM. A sensitive ELISA for the detection of human monocyte chemoattractant protein-1 (MCP-1). Immunol Invest 1992; 21: 39-45.

[13] Gelfand EW. Essential role of T lymphocytes in the development of allergen-driven airway hyperresponsiveness. Allergy Asthma Proc 1998; 19: 365-9.

[14] Grunig G, Warnock M, Wakil AE, et al. Requirement for IL-13 independently of IL-4 in experimental asthma. Science 1998; 282: 2261-3.

[15] Wills-Karp M, Luyimbazi J, Xu X, et al. Interleukin-13: central mediator of allergic asthma. Science 1998; 282: 2258-61.

[16] Takeda K, Kishimoto T, Akira S. STAT6: its role in interleukin 4mediated biological functions. J Mol Med 1997; 75: 317-26.

[17] Noben-Trauth N, Schultz LD, Brombacher F, Urban JFJr, GU H, Paul WE. An interleukin 4 (IL-4)-independent pathway for CD4+ T cell IL-4 production is revealed in IL-4 receptor-deficient mice. Proc Natl Acad Sci USA 1997; 94: 10838-43.

[18] Corry DB, Folkesson HG, Warnock ML, et al. Interleukin 4, but not interleukin 5 or eosinophils, is required in a murine model of acute airway hyperreactivity. J Exp Med 1996; 183: 109-17.

[19] Dabbagh K, Takeyama K, Lee HM, Ueki IF, Lausier JA, Nadel JA. IL-4 induces mucin gene expression and goblet cell metaplasia in vitro and in vivo. J Immunol 1999; 162: 6233-7.

[20] Sandford AJ, Chagani T, Zhu S, et al. Polymorphisms in the IL4, IL4RA, and FCERIB genes and asthma severity. J Allergy Clin Immunol 2000; 106: 135-40.

[21] Lukacs NW, Miller AL, Hogaboam CM. Chemokine receptors in asthma: searching for the correct immune targets. J Immunol 2003; 171: 11-5.

[22] Proust B, Nahori MA, Ruffie C, Lefort J, Vargaftig BB. Persistence of bronchopulmonary hyperreactivity and eosinophilic lung inflammation after anti-IL-5 or IL-13 treatment in allergic BALB/c and IL-4Ralpha knockout mice. Clin Exp Allergy 2003; 33: 119. 31.

[23] Wilder JA, Collie DD, Wilson BS, Bice DE, Lyons CR, Lipscomb MF. Dissociation of airway hyperresponsiveness from immunoglobulin $\mathrm{E}$ and airway eosinophilia in a murine model of allergic asthma. Am J Respir Cell Mol Biol 1999; 20: 1326-34.

[24] Jatakanon A, Uasuf C, Maziak W, Lim S, Chung KF, Barnes PJ. Neutrophilic inflammation in severe persistent asthma. Am J Respir Crit Car Med 1999; 160: 1532-9.

[25] Jeffery PK. Structural and inflammatory changes in COPD: a comparison with asthma. Thorax 1998; 53: 129-36. 